\title{
Efficacy of cod liver oil as an adjunct to non-steroidal anti-inflammatory drug treatment in the management of osteoarthritis in general practice
}

\author{
Trevor Stammers, Bonnie Sibbald, Paul Freeling
}

\begin{abstract}
A double blind, placebo controlled trial was carried out to assess the efficacy of cod liver oil as an adjunct treatment to non-steroidal anti-inflammatory drugs (NSAIDs) in the management of osteoarthritis in general practice. Eighty six patients were given $10 \mathrm{ml}$ of either cod liver oil or olive oil placebo daily as a supplement to their regular NSAID treatment for 24 weeks. Patients were assessed by their general practitioner at four week intervals for joint pain/inflammation, overall interference with activities, and unwanted effects of treatment. Patients recorded on visual analogue scales their daily pain and the extent to which arthritis interfered with everyday activities. There was no significant benefit for the patients taking cod liver oil compared with those taking placebo.
\end{abstract}

Several hospital based studies have shown the effectiveness of eicosapentaenoic acid in the alleviation of the symptoms of rheumatoid arthritis. ${ }^{12}$ This therapeutic effect is thought to be due to the entry of the acid into the prostaglandin synthesis pathways to produce metabolites that reduce inflammation. ${ }^{34}$

An inflammatory component in osteoarthritis is widely acknowledged, ${ }^{5}$ and we recently suggested that eicosapentaenoic acid might be of benefit in treating this condition. ${ }^{6}$ We investigated the effectiveness of cod liver oil, which contains eicosapentaenoic acid, as an adjunct to non-steroidal anti-inflammatory drug (NSAID) treatment of osteoarthritis in general practice.

Patients and methods

A double blind, placebo controlled trial was carried out to assess the efficacy of cod liver oil as an adjunct treatment to NSAIDs in the management of osteoarthritis in general practice. The study group comprised 86 patients, aged 49-87 years, with a clinical diagnosis of osteoarthritis made by their general practitioner, and confirmed by radiology in $76(88 \%)$. These patients still had symptoms after taking NSAIDs for at least two weeks before entry to the study. On entry patients were randomly allocated to receive either $10 \mathrm{ml}$ olive oil placebo or $10 \mathrm{ml}$ cod liver oil containing $786 \mathrm{mg}$ of eicosapentaenoic acid in addition to their current NSAIDs, for 24 weeks. Non-steroidal anti- inflammatory drug treatment remained unchanged throughout the study.

Patients kept a daily diary of their drug dosage. They also assessed pain and interference with everyday activities on separate $10 \mathrm{~cm}$ visual analogue lines every day of every fourth week. The significance of the differences between the patients' visual analogue line scores in the groups receiving cod liver oil and olive oil was assessed with the Student's $t$ test.

Patients were assessed by their general practitioner every four weeks for overall interference with activities, joint pain/inflammation, and unwanted effects of treatment. Overall disability for the previous month was scored by the doctor on a seven point scale. This assessment was based on scanning patient's diary records and questioning patients directly about the degree of interference with everyday activities caused by symptoms. Joint pain/inflammation was similarly scored on a seven point scale, the score again being based on patients' diary records and direct questioning about the degree of pain that month. The significance of differences between the two groups was assessed by the MannWhitney U test.

Patients were also questioned by the doctor about the nature and duration of any unwanted effects of treatment. The severity of each of these was scored on a four point scale.

Blood samples for full blood count, erythrocyte sedimentation rate, urea, creatinine, and liver function tests were taken from each patient at weeks 1 and 24 .

\section{Results}

Forty four patients received cod liver oil and $\mathbf{4 2}$ received olive oil placebo. There were no significant differences in clinical characteristics

Table 1 Characteristics of patients

\begin{tabular}{llc}
\hline & $\begin{array}{l}\text { EPA* } \\
\text { group } \\
(n=44)\end{array}$ & $\begin{array}{l}\text { Placebo } \\
\text { group } \\
(n=42)\end{array}$ \\
\hline $\begin{array}{l}\text { No (\%) of men } \\
\text { Mean age (years) }\end{array}$ & $15(34)$ & $97(21)$ \\
$\begin{array}{l}\text { Mean duration of arthritis (years) } \\
\text { Mean number of joints affected }\end{array}$ & 14 & 69 \\
$\begin{array}{l}\text { Radiographic confirmation } \\
\text { (No (\%)) }\end{array}$ & 6 & 17 \\
$\begin{array}{l}\text { Mean number of months receiving } \\
\text { current NSAID* treatment }\end{array}$ & $39(89)$ & $37(88)$ \\
$\begin{array}{l}\text { No (\%) previously receiving } \\
\text { higher dose of current NSAID }\end{array}$ & 80 & 36 \\
\hline
\end{tabular}

${ }^{*}$ EPA=eicosapentaenoic acid; NSAID =non-steroidal antiinflammatory drug. 
(table 1), or in type or dosage of NSAIDs (table 2) between the two groups on entry to the study.

Doctors' assessments of patients' disability and pain showed no significant differences between the groups receiving cod liver oil and olive oil during the study.

Table 3 summarises the patient's assessments of pain and disability on $10 \mathrm{~cm}$ visual analogue lines. There were no significant differences between the groups receiving cod liver oil and olive oil in the amount by which the patients' pain and disability either improved or deteriorated during the study.

Twenty two patients failed to complete the study -13 in the group receiving fish oil and nine receiving olive oil. The reasons for withdrawal included: non-compliance ( 5 receiving cod liver oil, 3 olive oil); concomitant illness ( 5 cod liver oil, 2 olive oil); and gastrointestinal upset ( 1 cod liver oil, 3 olive oil). No reason for withdrawal was stated for two patients taking fish oil and one patient taking olive oil.

Twenty three patients reported unwanted effects of treatment to their doctor-13(30\%) in the group receiving fish oil and 10 (24\%) receiving placebo. The nature of these side effects varied considerably from gastrointestinal upset to dry skin, but no clear difference was discernible between the two groups.

Analysis of blood taken at the outset and conclusion of the study showed that there were no significant changes in patients' haematology, liver function, or renal function, with one exception. Alkaline phosphatase levels increased in eight patients-four from each group.

\section{Discussion}

These findings suggest that cod liver oil is not an effective treatment for osteoarthritis when

Table 2 Non-steroidal anti-inflammatory treatment on entry to study

\begin{tabular}{|c|c|c|c|c|c|c|}
\hline \multirow[b]{2}{*}{ Drug name } & \multicolumn{3}{|c|}{$\begin{array}{l}\text { EPA* group }(n=44) \\
\text { Daily dosage }(m g)\end{array}$} & \multicolumn{3}{|c|}{$\begin{array}{l}\text { Placebo group }(n=42) \\
\text { Daily dosage }(m g)\end{array}$} \\
\hline & No & Mean & Range & $N o$ & Mean & Range \\
\hline Azapropazone & 1 & 900 & - & 1 & 600 & - \\
\hline Diclofenac sodium & 9 & 92 & $25-150$ & 13 & 98 & $25-200$ \\
\hline Fenbufen & 0 & - & - & 2 & 900 & - \\
\hline Fenoprofen & 1 & 600 & - & 0 & - & - \\
\hline Flurbiprofen & 1 & 200 & - & 2 & 250 & $200-300$ \\
\hline Ibuprofen & 7 & 1200 & - & 7 & 1143 & $600-1800$ \\
\hline Indomethacin & 14 & 64 & $25-100$ & 5 & 70 & $25-100$ \\
\hline Ketoprofen & 1 & 200 & - & 0 & - & - \\
\hline Mefenamic acid & 1 & 1500 & - & 1 & 500 & - \\
\hline Naproxen & 6 & 625 & $250-1000$ & 6 & 625 & $250-1000$ \\
\hline Piroxicam & 3 & 20 & - & 5 & 18 & $10-20$ \\
\hline
\end{tabular}

${ }^{*} \mathrm{EPA}=$ eicosapentaenoic acid.

Table 3 Change from baseline in patients' visual analogue line $(V A L)$ diary scores of pain and disability. Values give the mean change $(S D)$ from baseline of the VAL score

\begin{tabular}{|c|c|c|c|c|c|}
\hline \multirow[t]{2}{*}{ Month } & \multirow{2}{*}{$\begin{array}{l}\text { Numbers of } \\
\text { patients* }\end{array}$} & \multicolumn{2}{|l|}{ Pain } & \multicolumn{2}{|c|}{ Disability } \\
\hline & & $\overline{E P A T}$ & Placebo & $E P A$ & Placebo \\
\hline $\begin{array}{l}\text { Two } \\
\text { Three } \\
\text { Four } \\
\text { Five } \\
\text { Six }\end{array}$ & $\begin{array}{l}35 \\
35 \\
31 \\
31 \\
29\end{array}$ & $\begin{array}{r}1(17) \\
-2(18) \\
-2(19) \\
2(19) \\
1(20)\end{array}$ & $\begin{array}{r}0(15) \\
-2(15) \\
-2(16) \\
-2(18) \\
-3(18)\end{array}$ & $\begin{array}{r}-1(18) \\
-2(19) \\
-1(16) \\
1(18) \\
-2(17)\end{array}$ & $\begin{array}{l}-1(11) \\
-2(16) \\
-4(16) \\
-3(20) \\
-4(15)\end{array}$ \\
\hline
\end{tabular}

A decline in the VAL score for pain or disability represents improvement in the patients' condition There were no significant differences ( $t$ test) in the VAL scores between the two groups. *Numbers of patients in each of the two treatment groups.

tEPA = eicosapentaenoic acid. used to supplement NSAID treatment in general practice.

This was a pragmatic trial reflecting the way in which general practitioners would, and are, using fish oil in the management of patients with osteoarthritis. Patients were not receiving a standard type and dose of NSAID before entry because a pilot study showed this to be both impractical and artificial in the general practice setting. ${ }^{6}$ It is unlikely that this lack of standardisation biased the results as there were no appreciable differences between the groups receiving fish oil and placebo in the types or dosages of patients' NSAID treatment on entry to study. The assessments of outcome were principally subjective, based on patients' opinions and doctors' clinical judgment, as is appropriate for a symptomatic condition evaluated in general practice. The absence of any significant differences in outcome between the two groups cannot be attributed to any systematic bias in reporting as both patients and doctors were unaware of which treatment the patient had received. If the fish oil was indeed efficacious we must conclude that the benefit was too small to be apparent to either the patients or their doctors.

Criticism has been levelled at the use of olive oil as a placebo in clinical trials of eicosapentaenoic acid. ${ }^{7}$ There is at least one report which suggests that olive oil itself is effective in rheumatoid arthritis, ${ }^{8}$ and if so, may also be of benefit in osteoarthritis. In this study, however, there was no demonstrable improvement in those receiving either cod liver oil or olive oil. It seems likely, therefore, that neither treatment is effective when used as an adjunct to NSAIDs.

Inflammation of joints is thought to be only one mechanism underlying pain and disability in osteoarthritis. It may be that in this study NSAID treatment abolished that component of morbidity attributable to inflammation, providing no further opportunity for any antiinflammatory properties of cod liver oil to be shown. Clinical trials in patients whose condition does not require regular NSAID treatment might therefore show cod liver oil to be efficacious. Such investigations are needed to assess fully the role of cod liver oil in the management of osteoarthritis.

We thank Seven Seas Limited for their support of this work. We are also grateful to the following general practitioners who conducted the study on our behalf: M Gallagher, M Irfran, A James, M Johnson, J Kolendo, T Pinker, D Sudhakar, V Tun, and $R$ Weston-Underwood.

1 Kremer JM, Jubiz W, Michalek A, et al. Fish oil fatty acid supplementation in active rheumatoid arthritis. Ann Intern Med 1987; 106: 497-503.

2 Kremer J, Michalek A, Linninger L, et al. Effects of manipulation of dietary fatty acids on clinical manifestamanipulation of dietary fatty acids on clinical manif

3 Lee T, Hoover R, Williams J, et al. Effect of dietary enrichment with eicosapentaenoic and docosahexaenoic acids on in vitro neutrophil and monocyte leukotriene generation and neutrophil function. $N$ Engl $\mathcal{F}$ Med 1985; 312: 1217-24.

4 Prescott A, Zimmerman G, Morrison A. The effects of a diet rich in fish oil on human neutrophils. Prostaglandins 1985; 30: 209-27.

5 Altman R, Gray R. Inflammation in osteoarthritis. Clin Rheum Dis 1985; 11: 353 .

6 Stammers T, Sibbald B, Freeling P. Fish oil in osteoarthritis. Lancet 1989; ii: 503.

7 Milner M. Fish oil for preventing coronary re-stenosis. Lancet 1989; ii: 693.

8 Darlington L, Ramsay N. Olive oil for rheumatoid patients? Br F Rheumatol 1987; 26 (suppl): 215. 